\title{
Pembuatan Website Biro Pendidikan Nurul Jadid dengan Sistem Framework sebagai Media Informasi Pendidikan di Pesantren
}

\author{
M. Syafiih ${ }^{1}$, Muhammad David Abdullah², Moch Ryan Purwanto ${ }^{3}$, \\ Mohammad Jafar Shodiq ${ }^{4}$, Mohammad Hijrah ${ }^{5}$, Moh Alif Putra Mawardi 6 , \\ Muhammad Yudi Nasirudin ${ }^{7}$ \\ Universitas Nurul Jadid, Probolinggo 1, 2, 3, 4, 5, 6, 7 \\ \{m.syafii01@gmail.com², abdullahdavid321@gmail.com², ryansintia123@gmail.com³ \\ jafarsho23@gmail.com4, putrahijrah131@gmail.com ${ }^{5}$, putrarozi46@gmail.com6, \\ muhammadyudinasirudin@gmail.com ${ }^{7}$ \}
}

Submission: 2021-04-22 Received: 2021-04-29 Published: 2021-04-30

\section{Keywords:}

Framework, Boarding School, Information Portal

\begin{abstract}
The Nurul Jadid Islamic Boarding School Education Bureau is one of the bureaus in charge of implementing education for Elementary Secondary Schools (DASMIN), which is fully responsible to the head of the pesantren. The work program carried out by the education bureau includes: (1) making the Annual Budget Needs Plan (RKAT) for primary to secondary schools, the work programs of all schools will be discussed at the beginning of each year to be used as a reference as the education bureau policy. (2) Take full responsibility for the implementation of Teaching and Learning Activities (KBM) of all formal schools in Nurul Jadid Islamic Boarding School. (3) As an evaluation and monitoring agency for Teaching and Learning Activities (KBM) in formal schools at the Nurul Jadid Islamic Boarding School Foundation. The Framework-based Education Bureau Web Application as an information medium in the Education Bureau needs and must be understood by all stakeholders in the Education Bureau, so there is a need for socialization and training of web applications at the Education Bureau. The training is very helpful in understanding the functions and benefits of the information web application at the Education Bureau. The targets of the training are all elements in the Education Bureau, school principals, school operators and IT managers in all schools in the Nurul Jadid Islamic Boarding School Foundation area.
\end{abstract}

\begin{tabular}{ll} 
Katakunci: & Abstrak. Biro Pendidikan Pondok Pesantren Nurul Jadid merupakan \\
Framework, & salah satu biro yang membidangi pelaksanaan pendidikan Dasar \\
Pondok & Menengah (DASMIN), yang bertanggung jawab penuh kepada \\
Pesantren, & kepala pesantren. Progrem kerja yang dilaksanakan oleh biro \\
Portal Informasi & pendidikan meliputi: (1) membuat Rencana Kebutuhan Anggaran \\
& Tahunan (RKAT) sekolah dasar sampai menengah, program kerja \\
& semua sekolah akan dibahas setiap awal tahun untuk dijadikan \\
& rujukan sebagai kebijakan biro pendidikan. (2) Bertanggung jawab \\
\hline
\end{tabular} 
penuh atas terlaksananya Kegiatan Belajar Mengajar (KBM) semua sekolah formal yang ada di Pondok Pesantren Nurul Jadid. (3) Sebagai badan evaluasi dan monitoring Kegiatan Belajar Mengajar (KBM) yang ada di sekolah formal yang ada di Yayasan Pondok Pesantren Nurul Jadid. Aplikasi Web Biro Pendidikan yang berbasis Framework sebagai media informasi yang ada di Biro Pendidikan perlu dan harus dipahami semua stakeholder yang ada di Biro Pendidikan maka perlu adanya sosialisasi dan pelatihan aplikasi web yang ada di Biro Pendidikan. Pelatihan sangat membantu atas pemahaman fungsi dan manfaat aplikasi web informasi yang ada di Biro Pendidikan. Sasaran pelatihan adalah semua unsur yang ada di Biro Pendidikan, kepala sekolah, operator sekolah dan pengelola IT yang ada di semua sekolah yang ada diwilayah Yayasan Pondok Pesantren Nurul Jadid

\section{Pendahuluan}

Pesantren merupakan lembaga pendidikan islam yang tertua di indonesia tempat para santri mendalami dan sekaligus mengamalkan ilmu agama islam dalam kehidupan sehari-hari, dimana santri menerima pendidikan agama melalui sistem pengajian atau madrasah yang sepenuhnya berada di bawah pengawasan dan pembinaan seorang atau beberapa orang kyai dengan ciri-ciri khas yang bersifat karismatik serta independen dalam segala hal (Koesoema \& Albertus, 2010). Lembaga pendidikan tertua saat ini dan dianggap sebagai produk budaya Indonesia yang asli/khas yang tidak ditemui di negara lain adalah pesantren, sebuah lembaga dapat disebut sebagai pondok pesantren jika memuat 5 indikator yang terkumpul dalam sebuah kompleks, yang disebut kompleks pesantren, indikator tersebut yaitu: (1) kyai (2) santri (3) asrama (4) masjid / surau ( 5) pengajian ilmu ilmu yang berisi ajaran-ajaran Islam. Pondok Pesantren Dibagi Menjadi Dua Yaitu Pondok Pesantren Salaf Dan Pondok Pesantren Modern. Pondok Pesantren Nurul Jadid Merupakan Pondok Pesantren Modern.

Pondok Pesantren Nurul Jadid adalah salah satu pondok pesantren terbesar di Jawa Timur, yang berdiri pada tahun 1948, tepatnya di Desa Karanganyar, Kacamatan Paiton, Kabupaten Probolinggo. Sebagai pondok pesantren besar, tentunya Pondok Pesantren Nurul Jadid mengupayakan semaksimal mungkin dalam menfasilitasi segala kebutuhan santri, pengurus pesantren, guru, dosen, mahasiswa dan siswa. Karena, sebuah kegiatan pondok pesantren tentunya akan lebih efektif jika didukung dengan adanya fasilitas yang memadai. Salah satu fasilitas yang disediakan oleh Pondok 
Pesantren Nurul Jadid ialah sarana dan prasarana sebagai suatu bentuk akomodasi agar kegiatan pesantren dan lembaga dibawahnya berjalan dengan lancar. . Pendidikan menjadi salah satu yang sangat menentukan terhadap perubahan sosial (Zuhriy, 2011). Pondok Pesantren Nurul Jadid menganut panca kesadaran santri meliputi 1) sadar beragamana 2) kesadaran berilmu 3) kesadaran bermasyarakat 4) kesadaran berorganisasi 5) kesadaran berbangsa dan bernegara. Serta adanya trilog1 santri 1) Memperhatikan kewajiban-kewajiban fardu 'Ain 2) Mawas diri dengan meninggalkan dosa besar 3) Berakhlaq baik kepada Allah dan makhluk (Faizin \& dkk, 2010).

Pondok Pesantren Merupakan Tempat Untuk Membentuk Serta Mendidik Generasi Muda, akan Tetapi Banyak Terjadi Permasalahan Dalam Pondok Pesantren Tersebut seperti Pondok Pesantren Nurul Jadid ini. Yayasan Pondok Pesantren Nurul Jadid ini bergerak pada sistem keagamaan dengan konsep kurikulum pondok pesantren modern, dimana dalam Pondok Pesantren Nurul Jadid ini terdapat beberapa Pendidikan, seperti Madrasah Tsanawiyah (MTS) Madrasah Aliyah (MA) Sekolah Menengah Pertama (SMP) Sekolah Menengah Atas (SMA) Sekolah Menengah Kejuruan (SMK) dan terdapat Perguruan Tinggi. Untuk mengikuti perkembangan teknologi yang sangat pesat tentunya Pondok Pesantren Nurul Jadid harus mengimbangi kebutuhan pekayanan yang lebih efektif dan efisien sehingga nantinya memberikan kemudahan kepada sanri dan wali santri. Melihat kondisi yang demikian perlu adanya membangun teknologi informasi yang ada kaitannya secara langsung dengan kegiatan belajar mengajar santri. Aplikasi yang akan dibangun merupakan sistem informasi Biro Pendidikan yang berbasis web framework

Untuk menyelesaikan permaslahan perlu Merancang Sistem Portal Biro Pendidikan Pondok Pesantren Nurul Jadid Menggunakan Basis Data Berupa Web Dan Framework. Dengan uraian diatas maka dapat dirumuskan bahwa bagaimana cara membuat sistem informasi berbasis web dan framework (Jaya \& Sahlinal, 2017):

1. Bagaimana membuat sebuah sistem informasi berbasis web yang mudah digunakan untuk membantu memberikan informasi aktifitas biro Pendidikan di Pondok Pesantren Nurul Jadid. 
2. Sistem informasi berbasis web pada Biro Pendidikan untuk mempermudah pembelajaran pada santri di Pondok Pesantren Nurul Jadid.

Melihat fakta tersebut, Biro Pendidikaan Nurul Jadid membutuhkan sebuah aplikasi yang nantinya akan memberikan informasi mengenai sarana dan prasarana Pondok Pesantren Nurul Jadid. Hal ini untuk memudahkan pengumpulan data santri pada biro pendidikan Nurul Jadid.

\section{Metode}

a. Kerangka konseptual penelitian

Kerangka konseptual penelitian adalah suatu bentuk kerangka yang bisa digunakan untuk pendekatan dalam memecahkan masalah. Kerangka penelitian ini merupakan suatu langkah-langkah yang bertujuan untuk mempermudah pemahaman yang dibuat dalam bentuk bagan. Adapun langkah-langkah sebagai berikut (Nadiyah \& Syafiih, 2020) :

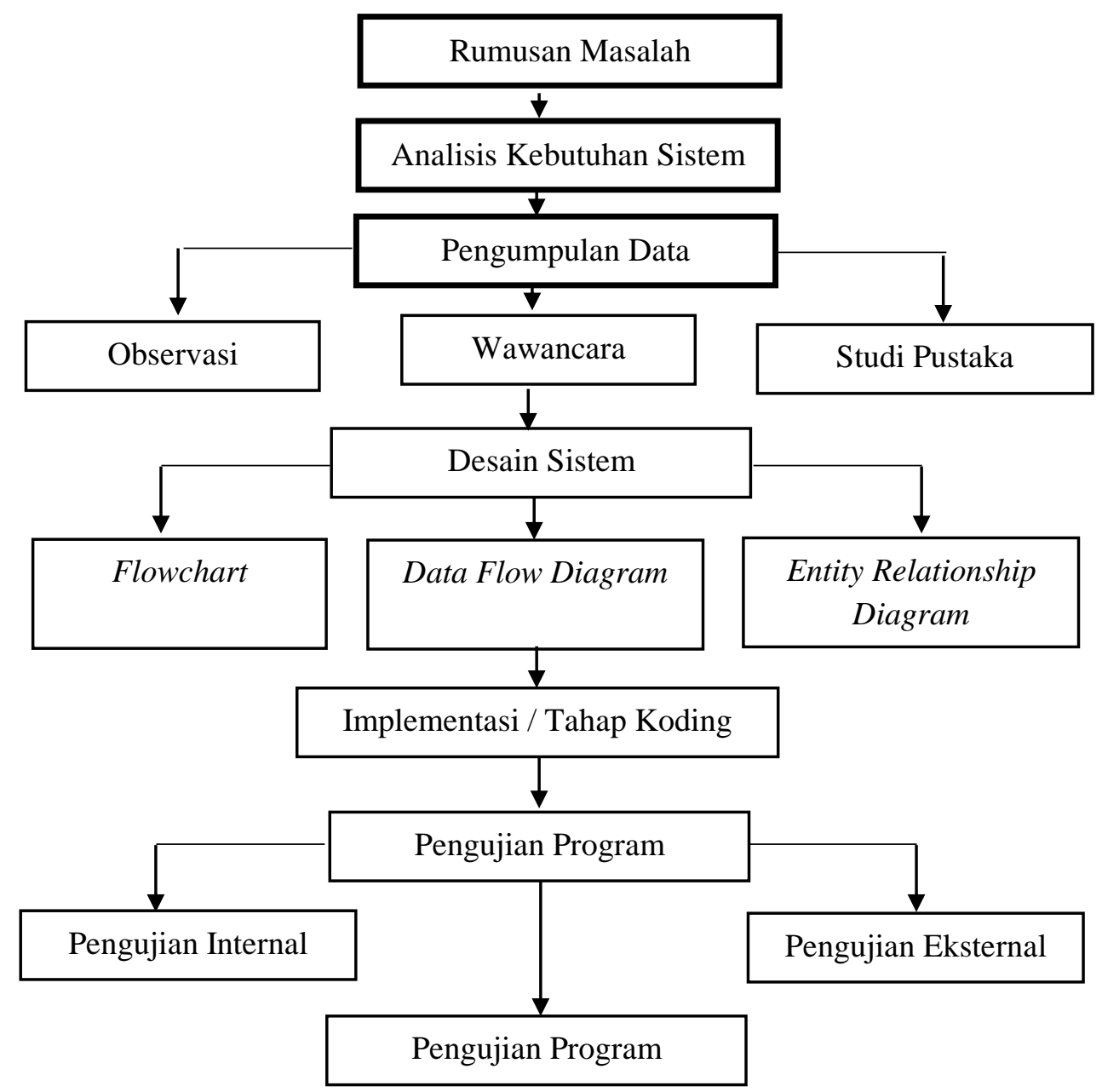




\section{Gambar 1. Bagan Konseptual Penelitian}

b. Metode pengembangan

Model pengembangan yang digunakan dalam penilitian ini adalah model waterfall atau juga disebut model air terjun. Metode ini sering digunakan karena dalam tahap pengembangan perangkat lunak dilakuan secara sistematis dan berurutan.

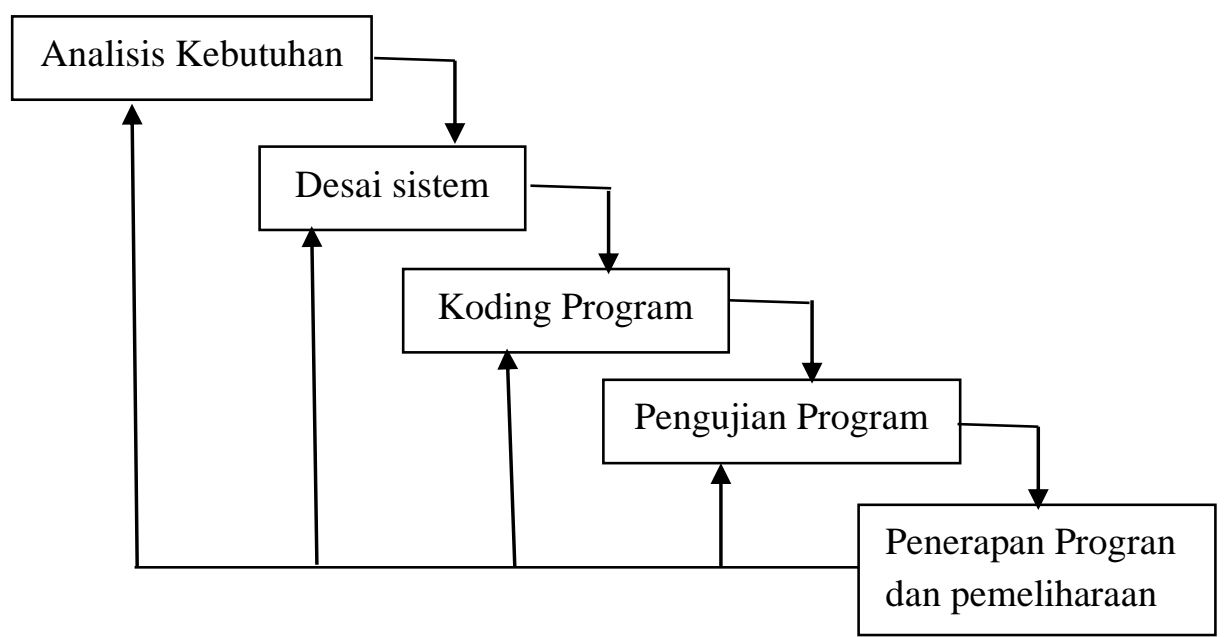

Gambar 2. Metode Waterfall

Model pengembangan yang digunakan dalam penilitian ini adalah model waterfall atau juga disebut model air terjun. Metode ini sering digunakan karena dalam tahap pengembangan perangkat lunak dilakuan secara sistematis dan berurutan.

c. Analisis kebutuhan sistem

Berdasarkan prosedur pengembangan perangkat lunak tahap awal adalah analisis kebutuhan sistem meliptui:

1. Observasi, dilakukan di Biro Pendidikan Pondok Pesantren Nurul Jadid.

2. Wawancara, dilaksanakan wawancara dengan kepala Biro Pendidikan Pondok Pesantren Nurul Jadid. 
3. Studi Pustaka, mempelajari beberapa metode dan memberikan landasan teori yang kuat melalui jurnal, buku-buku, artikel ilmiah, internet dan sumber-sumber lain yang dapat menambah informasi guna mendukung dalam penyelesaian karya ilmiah.

Tahap kedua desain sistem memberikan gambaran terhadap pengguna tentang bagaimana alur sistem yang akan dibuat. Tahap ketiga koding/pemrograman melakukan implementasi desain tersebut menjadi kode program. Tahap keempat pada pengujian ini merupakan tahapan yang paling terpenting dalam medel pengembangan waterfall. Pengujian dilakukan setelah program selesai. Tahap kelima Setelah melakukan uji sistem, tahap selanjutnya melakukan pemeliharaan terhadap perangkat lunak yang sudah dibuat.

\section{Hasil}

Setelah sesi pengisian materi yang telah dilakukan, maka dilakukan tahap selanjutnya yaitu evaluasi dan monitoring. Maka hal yang dapat kami lakukan untuk kedepannya yaitu mengadakan kegiatan serupa secara berkala agar bisa meningkatkan pengetahuan dan kemampuan pengguna tentang teknologi serta mendukung suksesnya Aplikasi Biro Pendidikan yang diharapkan bisa memudahkan santri untuk mendapatkan informasi tentang Pondok Pesantren Nurul Jadid. Kegiatan pengabdian ini mendapat sambutan dengan baik oleh para peserta, terbukti dengan antusiasnya peserta selama kegiatan ini berlangsung.

\section{Pembahasan}

Berdasarkan kegiatan ini didapatlah beberapa hasil dan pembahasan seperti sebagai berikut:

a. Tampilan Aplikasi Biro Pendidikan 


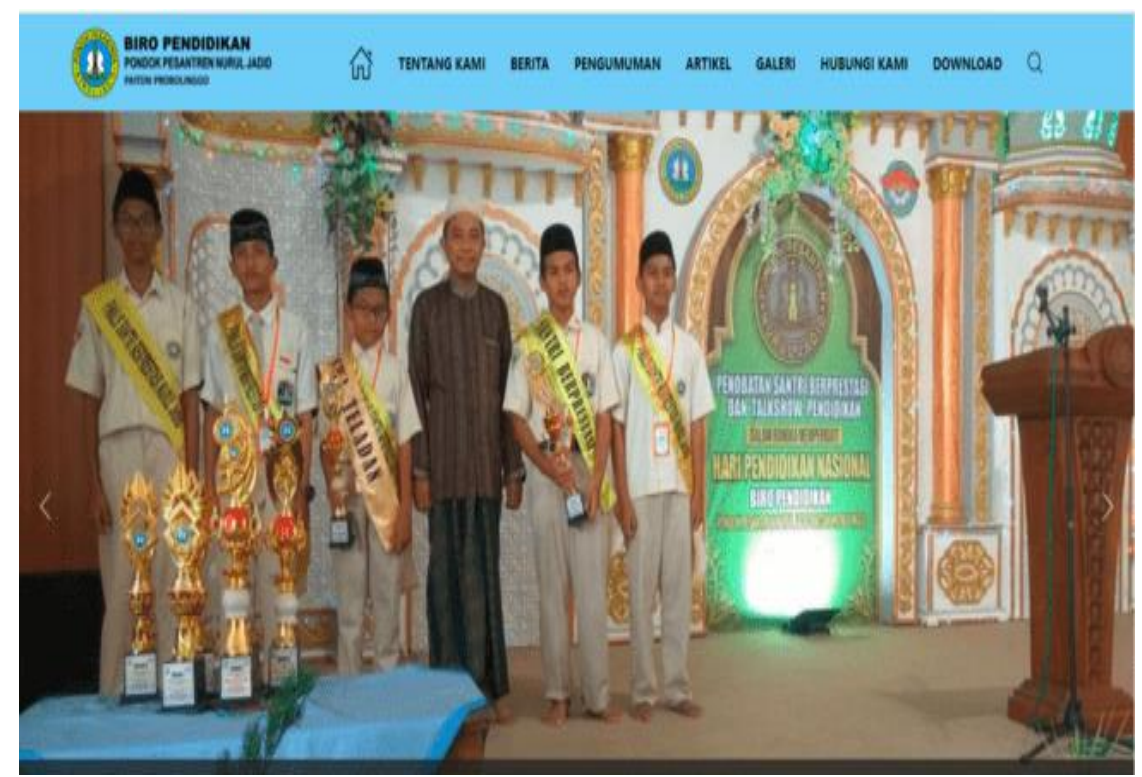

Gambar 3. Menu utama

Tampilan ini merupakan tampilan awal Aplikasi Biro Pendidikan. Dalam tampilan awal terdapat beberapa fitur yaitu Tentang kami, Berita, Pengumuman, Artikel, Galeri, Hubungi Kami dan Download.

b. Tampilan Tentang Kami

Dalam fitur ini terdapat beberapa menu yaitu:

PROFIL BIRO PENDIDIKAN PP. NURUL

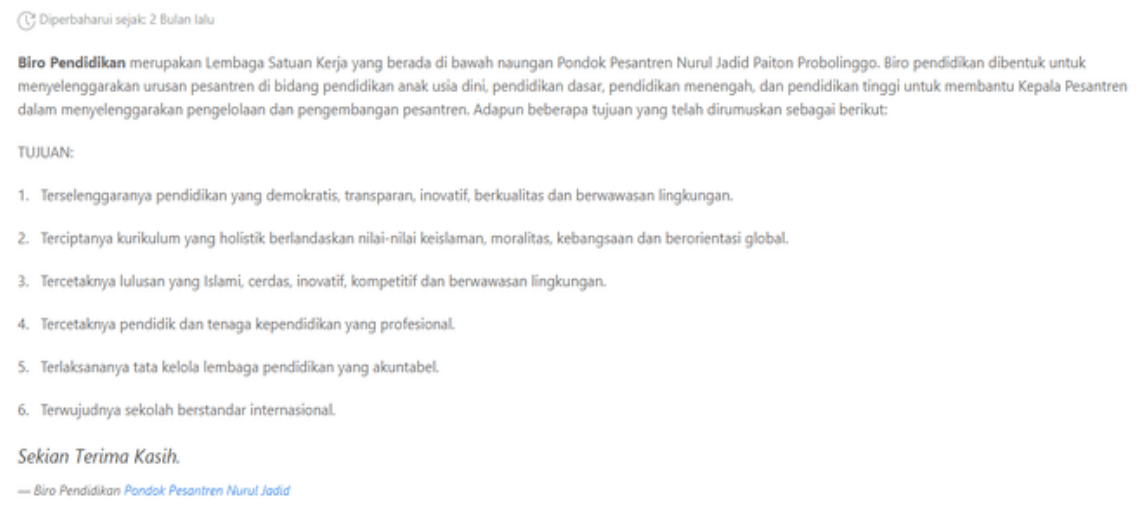

Gambar 4. Profil Biro Pendidikan

Dalam profil biro Pendidikan Pondok Pesantren Nurul Jadid menjelaskan tentang Biro Pendidikan Pondok Pesantren Nurul Jadid dan TujuanTujuannya. 
c. Berita
(18)
B. BIRO PENDIDIKAN

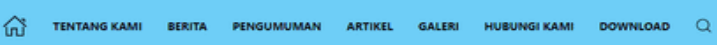
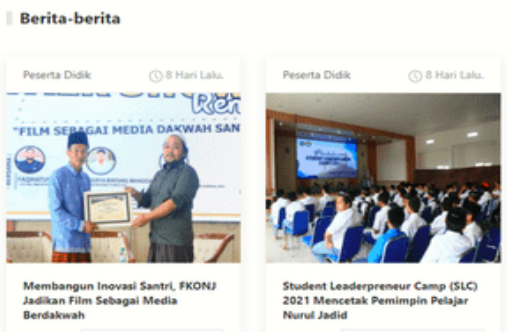

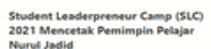

stunexapnra

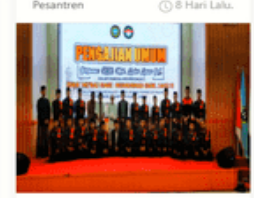

KH. Mon Zuhei Zaink lera' Mitrab.

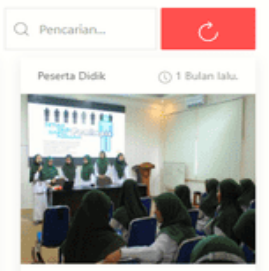

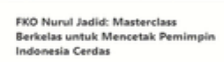

stumakasnva

Gambar 5. Profil Biro Pendidikan berita-berita tentang Lembaga Pendidikan

Dalam tampilan diatas adalah berita-berita tentang Lembaga Pendidikan Pondok Pesantren Nurul Jadid. Dalam Berita Biro Pendidikan Pondok Pesantren Nurul Jadid di bagi menjadi beberapa kategori yaitu:

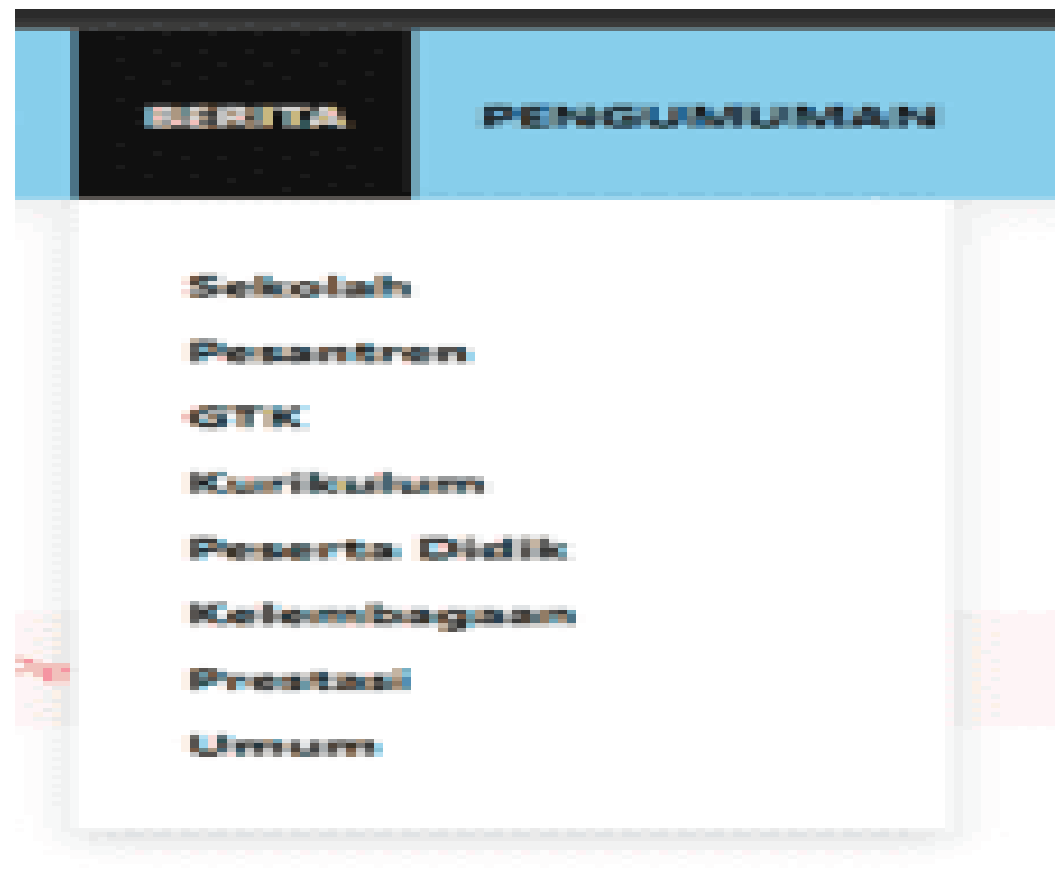

Gambar 6. Menu berita-berita tentang Lembaga Pendidikan

d. Pengumuman 


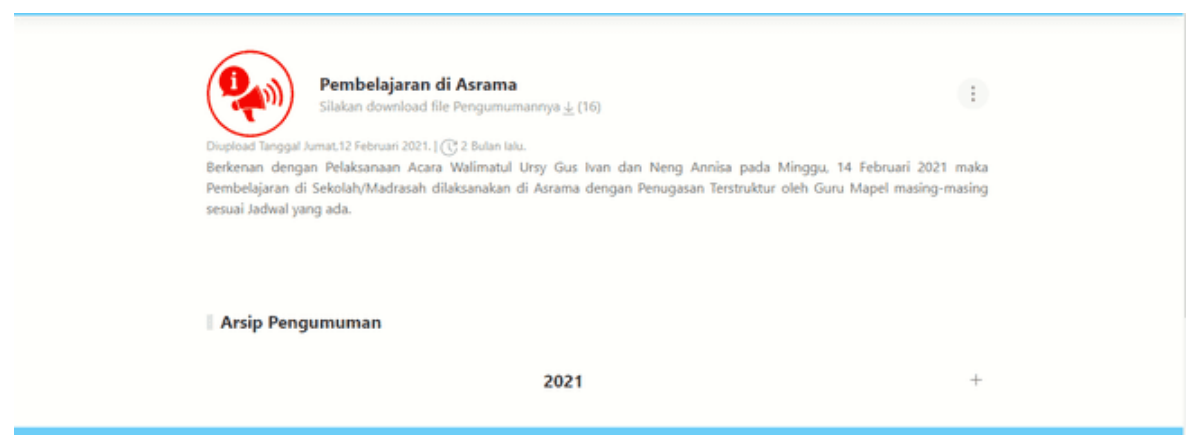

Gambar 7. Fitur Pengumuman

Dalam fitur pengumuman ini santri melihat jika ada pengumuman tentang Pondok Pesantren Nurul Jadid ataupun tentang pembelajaran di Pondok Pesantren Nurul Jadid.

e. Artikel

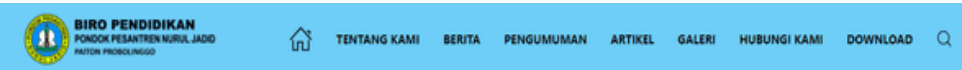

| Artikel-artikel

Gambar 8. Fitur Artikel

Dalam fitur Artikel ini Terdapat beberapa Kategori yaitu dengan sebagai Berikut

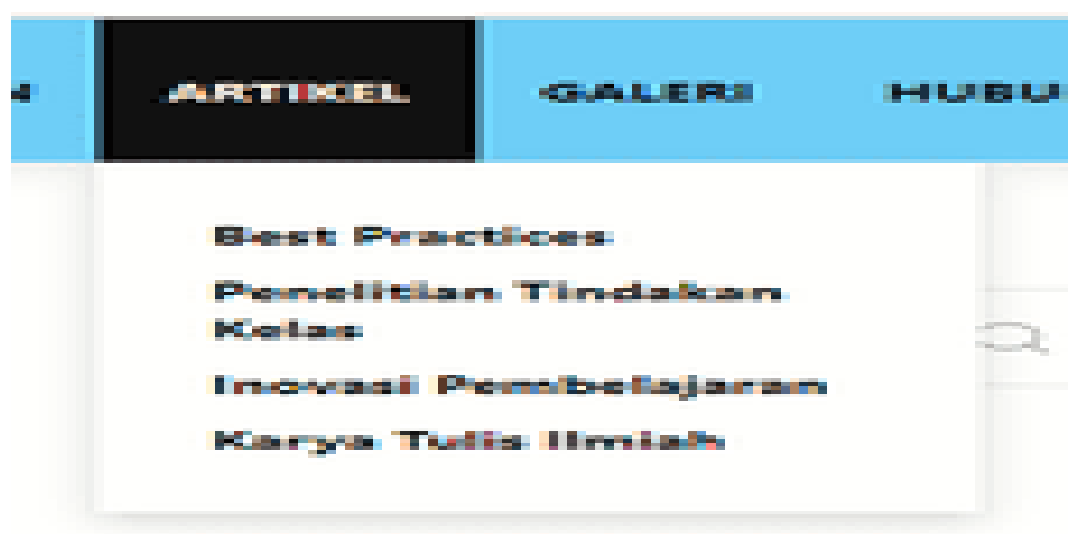


Gambar 9. Menu Fitur Artikel

Dalam kategori tersebut terdapat Artikel - Artikel tentang lembaga Kependidikan Pondok Pesantren Nurul Jadid. Tetapi ada beberapa kategori yang belum terisi Artikel.

f. Galeri

Album-album

Gambar 10. Galeri

Dalam galeri terdapat beberapa kategori album yaitu sebagai berikut :

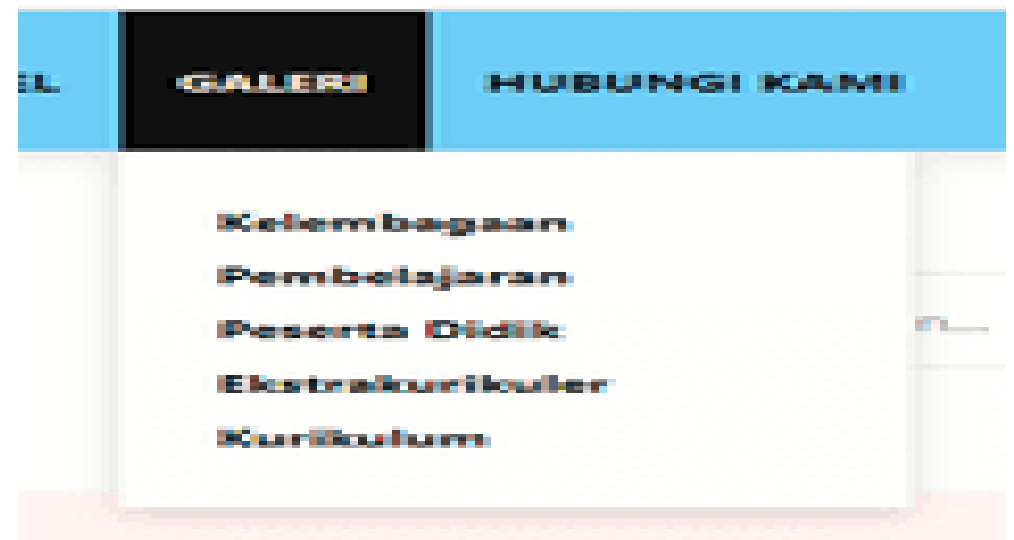

Gambar 11. Menu Galeri

Tetapi dalam setiap kategori album belum terdapat foto- foto dokumentasi 
g. Hubungi Kami

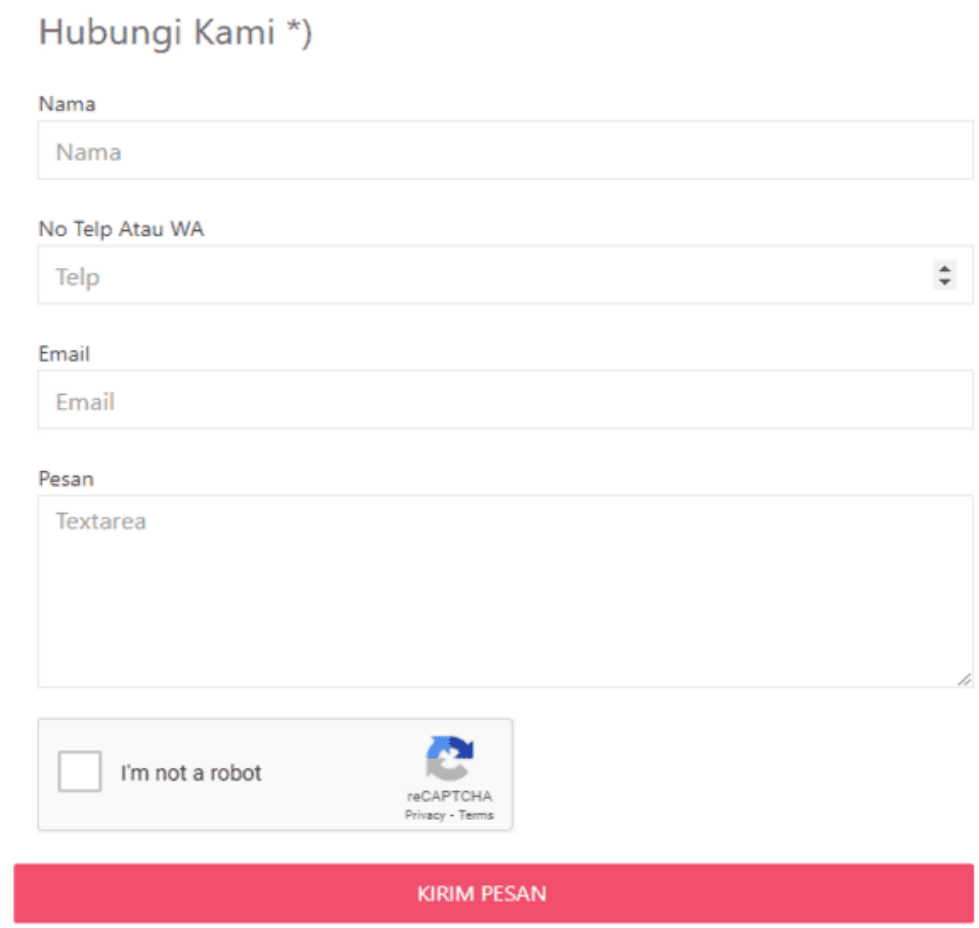

Gambar 12. Menu Hubungi Kami

Dalam tampilan diatas tersebut bisa digunakan untuk santri ataupun guru jika terdapat pesan, kritik dan saran untuk biro Pendidikan Pondok Pesantren Nurul Jadid. Dengan cara menginput Nama, No. Telp, Email, dan Pesan yang akan dikirimkan setelah mengklik kirim pesan maka pesan dengan otomatis pesan langsung terkirim secara real time ke Kepengurusan Biro Pendidikan Nurul Jadid.

h. Download 


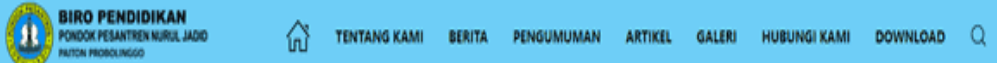

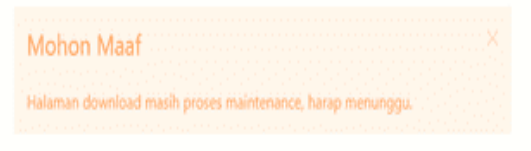

Gambar 13. Menu Download

\section{Kesimpulan}

Dari hasil pengabdian yang telah kami lakukan akan menghasilkan sebuah aplikasi yang berbasis web framework pada Biro Pendidikan Pondok Pesantren Nurul Jadid Paiton Probolinggo. Aplikasi tersebut bisa membantu biro pendidikan dalam mengelola pusat informasi dalam kegiatan belajar mengajar dan informasi yang disampaikan oleh biro pendidikan. Web tersebut juga bisa diakses oleh wali santri untuk mengetahui kurikulum serta kegiatan santri di pondok pesantren.

\section{Referensi}

Faizin, \& dkk. (2010). Profil Pondok Pesantren Nurul Jadid. Probolinggo: Pustaka Nurja.

Fitri, S. (2020). Pelatihan Pengelolaan E-Commerce pada Yayasan Pondok Pesantren Al-Hikmah Mangunreja Kabupaten Tasikmalaya . Jurnal Pengabdian Kepada Masyarakat, 273-279.

Jadid, P. P. (2020, Oktober 31). Kartu E-Bekal NJ Sebagai Akses Pelayanan Santri di Pondok Pesantren Nurul Jadid. 14 Februari 2021, p. 1.

Jaya, T. S., \& Sahlinal, D. (2017). Perancangan Kantor Digital Berbasis Framework dengan Metode Waterfall pada Politeknik Negeri Lampung. Jurnal Informatika:Jurnal Pengembangan IT (JPIT), 14-17.

Koesoema, D., \& Albertus. (2010). Pendidikan Karakter "Strategi Mendidik Anak di Zaman Global". Jakarta: Grasindo. 
Nadiyah, \& Syafiih, M. (2020). Pengembangan Aplikasi Pembelajaran Biologi Pada Filum Arthrophoda Dalam Kelas Insecta Augmented Reality Studi Kasus Dinas Pendidikan Kabupaten Probolingg. CYBER-TECHN, $1-9$.

Syafiih, M. (2020). PKM Peningkatan Keahlian Ibu PKK di Desa Karanganyar dengan Memanfaatkan Sumber Daya Alam (SDA) melalui Olahan Abon Ikan Laut dan Nugget. GUYUB: Journal of Community Engagement, 90-102.

Syafiih, M. (2020). PKM Peningkatan Keahlian Ibu PKK di Desa Karanganyar dengan Memanfaatkan Sumber Daya Alam (SDA) melalui Olahan Abon Ikan Laut dan Nugget. GUYUB: Journal of Community Engagement, 90-102.

Zuhriy, M. S. (2011). Budaya Pesantren dan Pendidika Karakter. Walisongo, 287-310. 